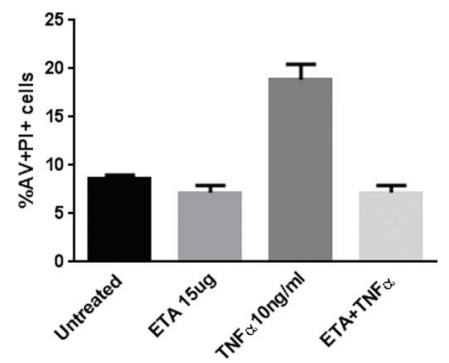

Abstract THU0022 Figure 1.
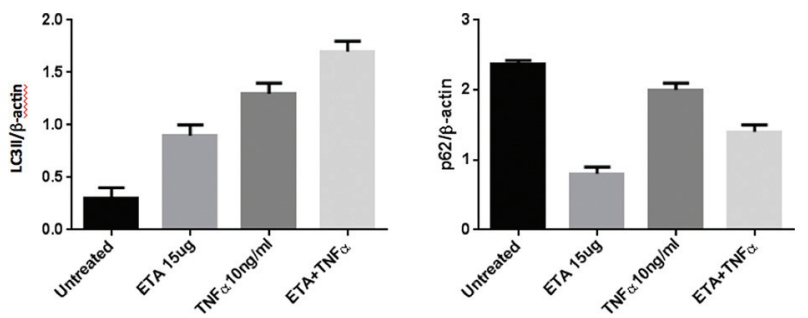

Abstract THU0022 Figure 1.

Disclosure of Interests: None declared

DOI: 10.1136/annrheumdis-2019-eular.6014

\section{THU0023 PARADOXICAL EFFECT OF INTERLEUKIN 1 BETA CYTOKINE ON COLLAGEN TYPE I SYNTHESIS IN OSTEOBLAST-LIKE CELLS}

Nur Adeelah Che Ahmad Tantowi, Jemma Kerns. Lancaster University, Lancaster Medical School, Lancaster, United Kingdom

Background: Osteoblasts are the bone forming cells that responsible for the synthesis of collagen type I and mineralization of bone during initial bone formation and later bone remodeling. Abnormalities in osteoblasts phenotype and activity occur in common bone diseases including osteoarthritis (OA). Studies showed that osteoarthritic osteoblasts secrete a collagen type I homotrimer of $\alpha 1$ chains, which is phenotypically distinct from the normal heterotrimer formed by two $\alpha 1$ chains and one $\alpha 2$ chain.

Cytokines released during $O A$ initiation or progression may interfere with osteoblastic function in the bone matrix. Interleukin 1 beta (IL-1B) is one of the major inflammatory cytokines implicated in the pathogenesis of OA; however, the biological response of osteoblasts to the cytokine is only partly understood.

Objectives: Our aims were to clarify the effects of $\mathrm{IL}-1 \beta$ on collagen type I synthesis in osteoblast-like cells and to explore further possible relationship between collagen type I synthesis and mineralization.

Methods: At confluence, MG63 osteoblast-like cells in osteogenic media were stimulated with low $(1 \mathrm{ng} / \mathrm{ml})$ or high $(10 \mathrm{ng} / \mathrm{ml})$ dose of recombinant human IL-1 $\beta$ at several incubation times; 1, 2, 3, 4 and 5 hours. Non-stimulated MG63 cells were grown as control at indicated time points. Cell viability was tested by using the PrestoBlue reagent. Total collagen production was evaluated by Picro-sirius red precipitation method. Secretion of homotrimer collagen type I alpha 1 (COL1A1) and mineralization at exposure time of 1-, 3- and 5- hour were determined by immunofluorescence staining of COL1A1 antibody and Alizarin Red S staining, respectively.

Results: IL-1 $\beta$ showed no statistical evidence in influencing cell viability at the time and dose tested compared to control. We found that $\mathrm{IL}-1 \beta$ significantly $(p<0.05)$ increased collagen content at short exposure time (1-hour), while significantly $(p<0.05)$ decreased collagen content at longer exposure time (5-hour), in a dose-dependent manner. Immunofluorescence staining showed increased of homotrimer COL1A1 at 1-hour exposure and decreased of homotrimer COL1A1 at 5-hour exposure of $\mathrm{IL}-1 \beta$ in the MG63 cells. IL-1 $\beta$ stimulated the formation of mineralized nodules at all exposure time.

Conclusion: We demonstrated for the first time of the paradoxical effect of IL-1 $1 \beta$ on collagen type I synthesis in osteoblast-like cells. Increased mineralization in low and high homotrimer type I collagen condition may possibly explain the abnormal mineralization in osteoarthritic bone.
Paradoxical role of $\mathrm{IL}-1 \beta$ in osteoblast may generate a different signal that regulates osteoblast markers expressed in the heterogenous subchondral bone changes in $\mathrm{OA}$. Understanding these mechanisms could pave the way towards targeted therapeutic interventions.

Acknowledgement: This study was supported by the Academy of Medical Sciences and the Material Science Institute Lancaster University.

Disclosure of Interests: None declared

DOI: 10.1136/annrheumdis-2019-eular.8291

\section{THU0024 INHIBITION OF CELL PROLIFERATION AND PROMOTION OF INTERLEUKIN-8 PRODUCTION BY T- 614 IN CULTURED HUMAN AORTIC ADVENTITIAL FIBROBLASTS}

Weiping Ci, Tian Wang. Beijing Anzhen Hospital, Capital Medical University, Rheumatology and Immunology, Beijing, China

Background: Takayasu's arteritis (TA) is an inflammatory fibrosing arteritis that affects predominantly the aorta and its main branches. Recently, growing evidence supports that adventitial fibroblasts play an essential role in vascular inflammation [1].Tumor necrosis factor- $\alpha$ (TNF- $\alpha$ ) can reportedly induce inflammation of vascular adventitial fibroblasts[2]. T-614 (iguratimod), a novel disease-modifying antirheumatic drug, has been widely used in rheumatoid arthritis in China and Japan [3]. However, the effect and mechanism of T-614 on TA have received little attention.

Objectives: We report the effects of T-614 on cell proliferation and interleukin-8 (IL-8) production in cultured human aortic adventitial fibroblasts (HAAF), and explored its possible effect on the treatment of TA.

Methods: HAAF were cultured with $0,5,50,100$, or $250 \mu \mathrm{g} / \mathrm{ml} \mathrm{T-614}$ in the absence or presence of $10 \mathrm{ng} / \mathrm{ml} \mathrm{TNF- \alpha}$ in vitro. Cell viability of HAAF was determined by a modified MTT assay. Supernatant IL-8 level was measured by enzyme linked immunosorbent assay.

Results: (1)After subculture, HAAF were polygonal or spindle-shaped under the microscope (Figure 1A, B).(2)In the presence of TNF- $\alpha$, compared with the contrast group, cell viability of HAAF significantly decreased in 50, 100, and $250 \mu \mathrm{g} / \mathrm{ml} \mathrm{T-614} \mathrm{treatment} \mathrm{groups} \mathrm{(OD} \mathrm{value:}$ $P<0.01, \quad P<0.001, \quad P<0.001$, respectively; survival fraction $(\mathrm{SF}): \quad P<0.05$ $P<0.001, P<0.001$, respectively) (Table I, Figure 2). However, there was no significant difference in cell viability between TNF- $\alpha$ stimulated and unstimulated groups at the same concentration of T-614. In the absence and presence of TNF- $\alpha, T-614$ suppressed HAAF cell viability dosedependently (OD value: $r=-0.915, P=0.000$ and $r=-0.926, P=0.000$, respectively; SF: $r=-0.897, P=0.000 ; r=-0.885, P=0.000$, respectively). (3)In the absence of TNF- $\alpha$, compared with the contrast group, IL-8 level in 5 and $100 \mu \mathrm{g} / \mathrm{ml} \mathrm{T-614}$ treated groups were significantly higher $(P<0.05)$; in the presence of TNF- $\alpha$, IL-8 level in 5,50 , and 100 $\mu \mathrm{g} / \mathrm{ml}$ T-614 treated groups were significantly higher $(P<0.001, P<0.001$ $P<0.01$, respectively); (Figure 3 ). There was a negative correlation between supernatant IL-8 level and the concentration of T-614 in groups stimulated with TNF- $\alpha(r=-0.670, P=0.000)$. TNF- $\alpha$ increased IL-8 level in the control group and various concentrations of $\mathrm{T}-614$ treated groups (all $P<0.001$ ).

Table I. Effects of T-614 on TNF- $\alpha$ stimulated cell viability of HAAF (OD value)

\begin{tabular}{lcc}
\hline T-614 $(\mu \mathrm{g} / \mathrm{ml})$ & OD value \\
\hline & $0 \mathrm{ng} / \mathrm{ml} \mathrm{TNF}-\alpha$ & $10 \mathrm{ng} / \mathrm{ml} \mathrm{TNF- \alpha}$ \\
\hline 0 & $0.424 \pm 0.038$ & $0.414 \pm 0.042$ \\
5 & $0.404 \pm 0.050$ & $0.440 \pm 0.054$ \\
50 & $0.347 \pm 0.061^{* * *}$ & $0.358 \pm 0.040^{* *}$ \\
100 & $0.267 \pm 0.034^{* * *}$ & $0.302 \pm 0.039^{* * *}$ \\
250 & $0.096 \pm 0.019^{* * *}$ & $0.092 \pm 0.009^{* * *}$
\end{tabular}

TNF- $\alpha$, tumor necrosis factor- $\alpha$; HAAF, human aortic adventitial fibroblasts. Data are shown as mean \pm SD of 3 independent experiments, each in triplicate. ${ }^{* \star *} P<$ $0.001,{ }^{* *} P<0.01$ vs. control group $(0 \mu \mathrm{g} / \mathrm{ml} \mathrm{T}-614)$ within each group alone.

Conclusion: T-614 can inhibit the proliferation of HAAF and promote IL-8 production; therefore, it may provide a new immunotherapeutic intervention for TA.

\section{REFERENCES:}

[1] Maiellaro, K. and W.R. Taylor, The role of the adventitia in vascular inflammation. Cardiovasc Res, 2007. 75(4): p. 640-8 
[2] He, Y., et al., SIRT6 inhibits TNF-alpha-induced inflammation of vascular adventitial fibroblasts through ROS and Akt signaling pathway. Exp Cell Res, 2017. 357(1): p. 88-97.

[3] Wei, Y., et al., Inhibitory Effect of a Novel Antirheumatic Drug T-614 on the IL-6-Induced RANKL/OPG, IL-17, and MMP-3 Expression in Synovial Fibroblasts from Rheumatoid Arthritis Patients. Biomed Res Int, 2015. 2015: p. 214683.
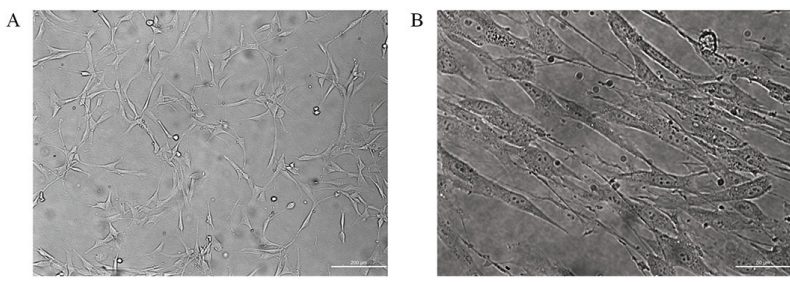

Figure 1.Clutured human aortic adventitial fibroblasts(HAAF) in vitro. HAAF were polygonal or spindle-shaped under the microscope. (A) Appearance of HAAF at generation 5, x100; (B) Appearance of HAAF at generation $5, x 400$

Abstract THU0024 Figure 1

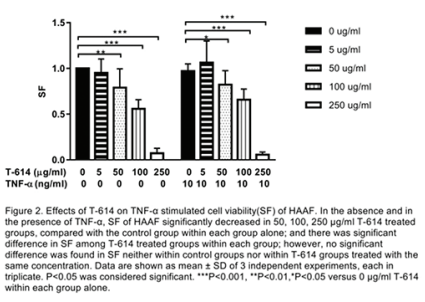

Abstract THU0024 Figure 2 .

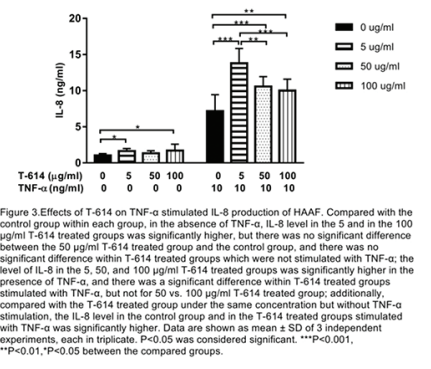

Abstract THU0025 Figure 2

Acknowledgement: Funding: This project was supported by grants from China International Medical Foundation(Z-2014-06-2-1636). The sponsors had no role in the study design, data collection and analysis, decision to publish, or preparation. Disclosure of Interests: None declared

DOI: 10.1136/annrheumdis-2019-eular.354

\section{THU0025 ANALYSIS OF POTENTIAL INTERACTIONS BETWEEN TENOCYTES AND SYNOVIAL FIBROBLASTS AFTER STIMULATION WITH CYTOKINES EXPRESSED WITHIN THE SYNOVIO-ENTHESAL COMPLEX}

Felix Dechant ${ }^{1}$, Klaus Frommer ${ }^{1}$, Neal L Millar ${ }^{2}$, lain Mcinnes $^{2}$, Stefan Rehart ${ }^{3}$, Ulf Müller-Ladner ${ }^{1}$, Elena Neumann' ${ }^{1}{ }^{1}$ Justus-Liebig-University Giessen, Dept. of Rheumatology and Clinical Immunology, Bad-Nauheim, Germany; ${ }^{2}$ University of Glasgow, Inst. of Infection Immunity and Inflammation, Glasgow, United Kingdom; ${ }^{3}$ Agaplesion Markus Hospital, Dept. of Orthopaedics and Trauma Surgery, Frankfurt, Germany

Background: Psoriatic arthritis (PSA) is frequently associated with enthesitis. It has been proposed that inflammatory processes at the synovioenthesal complex are involved in the pathogenesis of inflammatory arthritides including especially PsA. Besides IL-1 $\beta$ and TNF- $\alpha$, IL-15, IL-23 and IFN- $\gamma$ are cytokines expressed within the synovium, tendons and entheses and some of which are already used as therapeutic targets. While synovial fibroblasts (SF) are known key effector cells of cartilage destruction in inflammatory arthritides such as RA, tenocytes are a major component of tendons and entheses and play a central role in tendon inflammation observed in PsA.

Objectives: To investigate whether PSASF and tenocytes show significant interactions while being stimulated with the above cytokines alone as well as in combination with the aim to find out whether these may contribute to the pathogenesis of PsA.

Methods: SF were isolated from patients with PsA undergoing joint surgery. Human tenocytes were acquired commercially and isolated from hamstring tendon tissue of patients undergoing hamstring tendon $\mathrm{ACL}$ reconstruction. PsASF and tenocytes were stimulated with IL-1 $\beta$, TNF- $\alpha$, IFN- $\gamma, \mathrm{IL}-15$ and IL-23 alone and in combination. Direct cell co-culture experiments were performed at a 1:1 ratio of both cell types in paralle to experiments with single cell type cultures. IL-6 levels were measured by ELISA to quantify the immunological activation of the cells.

Results: PSASF as well as tenocytes showed strong responses to IL-1 $\beta$ (tenocytes $\uparrow 173$-fold, $\mathrm{n}=3$; PSASF $\uparrow 56$-fold, $\mathrm{n}=3$ ) and TNF- $\alpha$ (tenocytes $\uparrow 10$-fold, $\mathrm{n}=3$; PSASF $\uparrow 9$-fold, $\mathrm{n}=3$ ) stimulation regarding $\mathrm{IL}-6$ secretion. IFN- $\gamma$ alone had only minimal effects on both cell types but acted synergistically when applied together with $\mathrm{IL}-1 \beta$ (tenocytes $\uparrow 218$-fold, $\mathrm{n}=3$; PsASF $\uparrow 129$-fold, $n=3$ ) and TNF- $\alpha$ (tenocytes $\uparrow 24$-fold, $n=3$; PsASF $\uparrow 19$ fold, $\mathrm{n}=3)$. IL-15 and IL-23 alone showed no effect but the data suggest a small antagonistic effect against IL- $1 \beta$ (tenocytes IL-15 $\downarrow 21 \% / \mathrm{LL}-23$ $\downarrow 27 \%, n=3$; PsASF IL-23 $\downarrow 19 \%, n=3)$ and TNF- $\alpha$ induced IL- 6 secretion. Overall, PsASF and tenocytes showed similar responses in the single cell type stimulation experiments. Co-culturing PsASF and tenocytes did not reveal any synergistic or antagonistic interactions in regards to any of the cytokines used.

Conclusion: Our data suggest that tenocytes and PsASF do not interact in a way that would promote inflammation within the synovio-enthesal complex. Also, as far as the induction of IL-6 is concerned, PsASF and tenocytes are not major target cells of IL-15 and IL-23. IFN- $\gamma$, however may be able to promote inflammation in combination with other cytokines in both cell types.

Disclosure of Interests: Felix Dechant: None declared, Klaus Frommer: None declared, Neal L Millar: None declared, lain McInnes Grant/research support from: AstraZeneca, Celgene, Compugen, Novartis, Roche, UCB Pharma, Consultant for: AbbVie, Celgene, Galvani, Lilly, Novartis, Pfizer UCB Pharma, Stefan Rehart: None declared, Ulf Müller-Ladner Grant research support from: Projekt supported by an unrestricted educational grant from Celgene $\mathrm{GmbH}$., Elena Neumann: None declared

DOI: 10.1136/annrheumdis-2019-eular.7148

\section{THU0026 TARGETING SYNOVIAL FIBROBLASTS IN RHEUMATOID ARTHRITIS BY PEFICITINIB AND FILGOTINIB}

Magnus Diller', Rebecca Hasseli ${ }^{1}$, Iris Aykara ${ }^{1}$, Marie Hülser ${ }^{1}$, Stefan Rehart ${ }^{2}$, Ulf Müller-Ladner ${ }^{1}$, Elena Neumann ${ }^{1} .{ }^{1}$ Campus Kerckhoff, Justus-Liebig-University Gießen, Dept. of Rheumatology and Clinical Immunology, Bad Nauheim, Germany, ${ }^{2}$ Agaplesion Markus Hospital, Dept. of Orthopaedics and Trauma Surgery, Frankfurt, Germany

Background: The Janus kinase inhibitors (JAKi) peficitinib and filgotinib are currently examined in clinical trials for treatment of rheumatoid arthritis. Both inhibitors are well tolerated up to doses causing Cmax values higher than $1 \mu \mathrm{M}[1,2]$. This is in contrast to the approved dosages of tofacitinib and baricitinib reaching $\mathrm{Cmax}$ values below $0.5 \mu \mathrm{M}[3,4]$. How ever, it is not known if the higher concentrations of peficitinib or filgotinib offer a benefit in treatment of rheumatoid arthritis.

Objectives: The aim of the study compared the effect of different JAKi on inflammatory response and functional behavior of fibroblast-like synoviocytes from patients with RA (RASF).

Methods: Human RASF were isolated and pretreated with JAKi. After stimulation with IL-1 $\beta$ and JAKi with/without soluble IL-6 receptor (SIL-6R) the levels of IL- 6 and MMP-3 were measured in supernatants by ELISA. The effect of different JAKi on proliferation of RASF was determined by a BrdU-incorporation assay. The influence of peficitinib on migration of RASF towards a FCS gradient was examined. For short-term adhesion assays, cells were treated with JAKi, detached and seeded in culture plates. The plates were extensively shaken and adherent RASF quantified by counting crystal violet stained cells. Cell viability, cytotoxicity and apoptosis were measured using commercially available assays.

Results: The IL-1 $\beta(10 \mathrm{ng} / \mathrm{ml})$ dependant IL-6 release of RASF was decreased by peficitinib $(62 \%, p<0.001)$ and by filgotinib $(30 \%, p<0.05$, $\mathrm{n}=7)$ at $5 \mu \mathrm{M}$. Peficitinib also decreased the IL-6 release at $1 \mu \mathrm{M}(24 \%$, $\mathrm{n}=7$ ). In contrast to filgotinib, the JAK-inhibition with peficitinib reduced 